ABSTRACT: Several studies have reported the occurrence of sensory neuropathy with exposure to chlorpyrifos and other organophosphorus insecticides, at levels not associated with overt toxicity. We evaluated 113 chemical workers, including 53 of $66(80 \%)$ eligible chlorpyrifos workers and 60 of $74(81 \%)$ randomly selected referent workers, to identify evidence of sensory neuropathy or subclinical neuropathy. Compared to referents, chlorpyrifos subjects had significantly longer duration of work in chlorpyrifosexposed areas (9.72 vs. 0.01 years; $P<0.0001)$, greater cumulative chlorpyrifos exposure (64.16 vs. $0.69 \mathrm{mg} / \mathrm{m}^{3} \cdot$ day; $\left.P<0.0001\right)$, higher urine 3,5,6-trichloro-2-pyridinol (TCP) excretion (108.6 vs. $4.3 \mu \mathrm{g} / \mathrm{g}$ creatinine; $P<0.0001)$, and lower plasma butyrylcholinesterase (BuChE) activity (7281 vs. $8176 \mathrm{mU} / \mathrm{ml} ; P=0.003$ ). Despite exposures among chlorpyrifos subjects to levels at which well-described physiological effects on B-esterases exist, the frequency of symptoms or signs of neuropathy did not differ significantly between groups, and the only 2 subjects fulfilling criteria for confirmed neuropathy were both in the referent group. Mean nerve conduction study results were comparable to established control values and did not differ significantly between groups. We found no evidence of sensory neuropathy or isolated peripheral abnormalities among subjects with long-term chlorpyrifos exposure at levels known to be associated with the manufacturing process.

Muscle Nerve 29: 677-686, 2004

\title{
ABSENCE OF SENSORY NEUROPATHY AMONG WORKERS WITH OCCUPATIONAL EXPOSURE TO CHLORPYRIFOS
}

\author{
JAMES W. ALBERS, MD, PhD, ${ }^{1,2,3}$ DAVID H. GARABRANT, MD, MPH, ${ }^{3}$ \\ SARAH SCHWEITZER, MS, ${ }^{4}$ RICHARD P. GARRISON, PhD, ${ }^{3}$ \\ RUDY J. RICHARDSON, ScD, ${ }^{1,3}$ and STANLEY BERENT, PhD ${ }^{1,2,3}$ \\ ${ }^{1}$ Department of Neurology, University of Michigan Medical School, \\ Ann Arbor, Michigan, USA \\ ${ }^{2}$ Neurobehavioral Toxicology Program, University of Michigan, \\ Ann Arbor, Michigan, USA \\ ${ }^{3}$ Department of Environmental Health Sciences, School of Public Health, \\ University of Michigan, Ann Arbor, Michigan, USA \\ ${ }^{4}$ Department of Biostatistics, School of Public Health, University of Michigan, \\ Ann Arbor, Michigan, USA
}

Accepted 18 December 2003

Exposure to sufficient amounts of certain organophosphorus (OP) compounds may be followed by development of a rapidly progressive distal axonopathy affecting the peripheral nervous system and the spinal cord. ${ }^{31}$ A prominent motor neuropathy is the

Abbreviations: AChE, acetylcholinesterase; BuChE, butyrylcholinesterase; $\mathrm{Cr}$, creatinine; CV, conduction velocity; NCS, nerve conduction study; OP organophosphorus; OPIDN, organophosphorus-induced delayed neurotoxicity; RBC, red blood cell; TCP, 3,5,6-trichloro-2-pyridinol

Key words: chlorpyrifos; insecticides; nervous system; neuropathy; neurotoxicity

Correspondence to: J. W. Albers, Department of Neurology, 1C325/0032 University Hospital, University of Michigan Health System, 1500 East Medical Center Drive, Ann Arbor, Ml 48109-0032; e-mail: jwalbers@umich.edu

(C) 2004 Wiley Periodicals, Inc.

Published online 11 March 2004 in Wiley InterScience (www.interscience. wiley.com). DOl 10.1002/mus.20007 primary component of the syndrome referred to as organophosphorus-induced delayed neurotoxicity (OPIDN). OPIDN is initiated by the phosphorylation of neurotoxic esterase, followed by "aging" of the phosphoryl-enzyme complex, a step required to produce the toxic effect. ${ }^{29}$ Although widely studied in laboratory animals, ${ }^{10,27,35}$ OPIDN rarely has been observed in humans since the late 1950s, and only a few cases are reported annually worldwide, typically in association with massive suicidal ingestion of an OP insecticide. ${ }^{20,31,39}$ At present, the most convincing evidence associating chlorpyrifos with OPIDN in humans involves massive exposure levels that produce life-threatening cholinergic effects attended by substantial inhibition of plasma butyrylcholinester- 
ase (BuChE) and red blood cell acetylcholinesterase (RBC AChE). ${ }^{30,31}$

There also are descriptions of peripheral nervous system disorders other than OPIDN developing with exposure to OP compounds. ${ }^{7,22,23,32,45}$ These problems include sensory neuropathy or mild sensory abnormalities demonstrable on quantitative sensory testing. Although some patients who develop OPIDN have mild sensory loss, prominent or exclusive sensory loss is not an accepted feature of OPIDN. ${ }^{31}$ Reports of sensory neuropathy associated with OP exposure are important because they raise questions about a form of peripheral neurotoxicity dissimilar to OPIDN and the established toxicological characteristics of OP insecticides. The peripheral nervous system effects attributed to long-term, low-level exposure to OP pesticides are considered by most scientists to remain in question, ${ }^{6,48}$ although the published reports have raised the possibility that OPIDN is but one extreme of a spectrum of possible neurological consequences of exposure to these compounds.

The evidence that low-level exposures to OP insecticides produces sensory neuropathy is limited.6,7,18,25,26,28,41,45 Overall, studies to date have shown either no difference in the frequency of abnormal findings between exposed and nonexposed groups, ${ }^{6}$ minor symptoms or signs of unknown significance, ${ }^{7,32,45}$ no relationship between measured exposures and neurological function, ${ }^{26}$ or inconsistent findings across tests. ${ }^{22}$ In one study, ${ }^{26} \mathrm{OP}$ insecticide applicators reported more neurological symptoms (although not sensory) than did referents, but quantitative vibration thresholds were not related to exposure measures. In another study, clinical evaluations showed only subtle signs of unclear significance. ${ }^{7}$ Sheep dippers who handled OP concentrate showed a high prevalence of sensory symptoms and a weakly positive association between neurological symptoms and cumulative OP exposure; however, neither thermal nor vibration sensory thresholds were associated with cumulative exposure measures. ${ }^{32}$ A subsequent study by several of the same investigators reported that sheep farmers and dippers thought to have neuropathy in the earlier investigation showed evidence of a small-fiber neuropathy on thermal threshold testing, ${ }^{22}$ but only 7 subjects had clinical signs of neuropathy. In contrast, OP pesticide applicators showed abnormal vibration thresholds in the hands compared to referent values, findings consistent with a large-fiber neuropathy. ${ }^{45}$ The existing studies of peripheral nerve function lack evidence of specific symptoms or robust clinical signs. ${ }^{8}$ Critical reviews of the existing literature have concluded that peripheral nervous system findings occurred only when OP poisoning was acute and severe, ${ }^{11}$ and that findings attributed to low-level OP exposures were mild, inconsistent, and unexplained. ${ }^{28}$

A committee convened by the United Kingdom Department of Health concluded that exposure to OPs at doses lower than those causing frank cholinergic toxicity either do not cause neuropathy or do so only rarely. ${ }^{48}$ The present study was undertaken in response to recommendations by a panel of scientists convened by Dow AgroSciences in cooperation with the U.S. Environmental Protection Agency that persons engaged in the manufacture or professional application of chlorpyrifos be targeted for additional study of neurological function. ${ }^{3}$ This population was selected because they have measurable chlorpyrifos exposures at levels believed to have adverse effects and in which confounders could be assessed.

We sought to determine whether exposure to chlorpyrifos at levels associated with various aspects of manufacturing produces identifiable neurotoxicity. The prospective hypothesis under study was that workers with long-term occupational exposure to chlorpyrifos develop dose-related subclinical or clinically evident adverse effects, including peripheral neuropathy. Results from the longitudinal prospective cohort study will be reported separately. ${ }^{4}$ In this study we report in detail the baseline cross-sectional data reflecting the peripheral nervous system evaluations designed to identify subclinical or clinically evident neuropathy.

\section{METHODS}

Study Design. Two groups of Dow Chemical Company employees were eligible for participation. The first group consisted of workers involved in the various aspects of manufacturing chlorpyrifos. Saran (i.e., clear plastic-film wrapping material) manufacturing workers, who had no current occupational exposure to chlorpyrifos or other neurotoxicants, were chosen as a referent population. The use of this referent group allowed us to control for the effects of employment in the chemical industry, including factors related to employee selection and effects of employment. Personnel masked to the exposure group membership of any given subject performed all clinical examinations and biomarker evaluations. Examinations were scheduled so that the investigators examined workers on a given day without any indication of the group to which the individual subject belonged. Examinations took place during a 2-month period that occurred during a period of potential chlorpyrifos exposure for the chlorpyrifos subjects. All participants read and signed an in- 
formed consent form indicating their willingness to participate. The study was approved by the University of Michigan Institutional Review Board for $\mathrm{Hu}$ man Subject Research and the Dow Chemical Company Human Subject Review Board.

Subjects. The major eligibility criteria included employment at Dow Chemical Company; age 18-65 years; ability to read, understand, and sign informed consent forms; and capability to complete the testing protocol. All chlorpyrifos manufacturing workers employed on September 1, 1999 in any of the buildings involved in chlorpyrifos production and product formulation/packaging were asked to participate. Fifty-three of the 66 eligible chlorpyrifos workers $(80 \%)$ participated. Seventy-four Saran workers were chosen at random and asked to participate; of these, $60(81 \%)$ participated.

Participants were interviewed regarding demographic information; personal medical history, including neurological disorders, diabetes, thyroid disease, vascular disease, trauma, back problems, and medications; family history of neurological diseases; and social history, including use of alcohol and possible nonoccupational exposure to insecticides. No subject was excluded because of a physician-diagnosed condition. In terms of characteristics important to the evaluation of the nervous system, the groups were comparable in terms of age, gender, anthropometric features, alcohol use, smoking history, and medication use (1 subject in each group was taking a medication with neurotoxic potential, and 1 subject in the chlorpyrifos group had taken a chemotherapeutic medication with neurotoxic potential). Overall, participants were in early middle age, mostly male, and white $(90 \%)$. They were of average height but above average weight, and $47 \%$ had a body mass index exceeding 29.0, the level considered obese. Fewer chlorpyrifos subjects reported hand injury or hand fracture (most commonly, remote fracture of individual digits) than did referents (11 vs. 33; $P=0.00023$ ), but the groups showed a comparable frequency of other medical problems, including diabetes mellitus (1 subject in each group), renal disease, thyroid disease, rheumatoid arthritis, and back problems.

Chlorpyrifos Exposure. Potential neurotoxic exposures were assessed by systematic review of the chemicals used in each manufacturing area from which the subjects were selected (both chlorpyrifos and Saran facilities) to identify those chemicals that have neurotoxic properties. No significant exposures to these chemicals were indicated from review of standard work procedures and historical industrial hygiene records, including personal air sampling data. Estimates of ambient chlorpyrifos exposure were derived from industrial hygiene measurements that were compiled for similarly exposed groups of workers, and geometricmean exposure levels were calculated for each of these groups. These mean data were used to establish historical cumulative chlorpyrifos exposure estimates from the time of initial employment to the baseline examination. The industrial hygiene measures showed significant differences between the chlorpyrifos subjects and the referent subjects for duration of work in chlorpyrifos-exposed areas (9.72 vs. 0.01 years; $P<0.0001)$ and for historical cumulative chlorpyrifos exposure (64.16 vs. $0.69 \mathrm{mg} / \mathrm{m}^{3} \cdot$ day; $\left.P<0.0001\right)$. One chlorpyrifos subject had no identifiable exposure but met all criteria for inclusion. The next least-exposed chlorpyrifos subject had 1.27 years of exposure.

Chlorpyrifos exposure was assessed contemporaneously with our evaluation by measuring urinary excretion of 3,5,6-trichloro-2-pyridinol (TCP), plasma butyrylcholinesterase (BuChE) activity, and red blood cell cholinesterase (RBC AChE) activity. Urine TCP, a metabolite of chlorpyrifos, was collected during the study period and during normal operations. It was reported for an overnight collection (micrograms TCP) and standardized to urinary creatinine (Cr) excretion (TCP/Cr; micrograms TCP per gram of creatinine). Plasma BuChE activities (milliunits per milliliter) were obtained monthly and were averaged over the 4-month study period. RBC AChE activities were obtained on the day of examination. The biological exposure measures showed significant differences in exposure between the chlorpyrifos group and the referent group for measures of urine TCP $/ \mathrm{Cr}(108.6$ vs. $4.3 \mu \mathrm{g} / \mathrm{g} \mathrm{Cr}$; $P<0.0001)$ and average plasma BuChE activity (7281 vs. $8176 \mathrm{mU} / \mathrm{ml} ; P=0.003$ ). RBC AChE activities did not differ significantly between groups (6923.19 vs. $6966.77 \mathrm{mU} / \mathrm{ml} ; P=0.77$ ).

Neurological Evaluation. Neurological examinations were performed on all subjects by the same boardcertified neurologist. A clinical interview was conducted to identify symptoms of neuropathy, such as loss of feeling, paresthesias, numbness or tingling, imbalance, or weakness. The neurological examination was used to identify the presence of clinically evident signs. Included was evaluation of selected cranial nerve function, strength (including bilateral intrinsic hand and foot muscles), station, gait, coordination, alternate-motion rate, presence of abnormal movements (tremor, fasciculations), sensation (dual simultaneous stimulation, von Frey monofila- 
ment at index finger and great toe, joint position sensation at great toe, pin-pain at index finger and great toe, vibration at index finger and great toe), muscle stretch reflexes (biceps brachii, brachioradialis, quadriceps, and gastrocnemius-soleus), and documentation of abnormal corticospinal tract signs.

Nerve Conduction Studies. Conventional nerve conduction studies were performed on the dominantside sensory (median, ulnar, and sural) and motor (median and peroneal) nerves. Antidromic sensory conduction studies used a $14-\mathrm{cm}$ distance between stimulation and recording electrodes, recording from digit II, digit $\mathrm{V}$, and the ankle, respectively. Sensory response amplitude (baseline to negativepotential peak), onset latency, and negative-peak latency were recorded. Median and peroneal motor conduction studies used a 7- and 9-cm distance from stimulation to recording electrodes, recording from the abductor pollicis brevis and extensor digitorum brevis muscles, respectively. Motor response amplitude (baseline to negative peak); onset latency for wrist, below-elbow, and ankle stimulation sites; and F-wave latency for antidromic stimulation at the wrist and ankle were recorded, and a median forearm conduction velocity was calculated. Identification of isolated abnormalities was based on published values using a comparable technique (Table 1).2,13,37 The values used to define abnormalities were equivalent to those used clinically at the University of Michigan Electromyography Laboratory, as defined for normal, healthy adults (approximately 95th percentile values). The sensory conduction velocities represent terminal conduction velocities, calculated from onset latencies. Limb temperature (palm and leg) was recorded and monitored during the evaluation, and limbs were warmed when necessary to maintain temperatures above $32^{\circ} \mathrm{C}$ (palm) and $31^{\circ} \mathrm{C}$ (foot). There were no significant group temperature differences.

Outcome Variables. Subclinical or clinically evident neuropathy was defined using a combination of abnormalities from the categories of symptoms, signs, and nerve conduction testing as consistent with standard clinical practice. ${ }^{16,17}$ "Probable" clinical neuropathy was defined as the presence of abnormalities consistent with a sensory or sensorimotor neuropathy in at least two of the following three categories: symptoms; peripheral sensation; or decreased ankle reflexes (trace or absent). Symptoms accepted as consistent with neuropathy included reports of persistent and symmetrical stocking or stocking-glove distribution numbness, tingling, or sensory loss. Because no subject reported persistent sensory symp- toms consistent with neuropathy, the definition was extended to include subjects with intermittent symmetrical stocking or stocking-glove distribution sensory symptoms. Signs of peripheral sensory dysfunction accepted as consistent with neuropathy included evidence of symmetrical stocking or stocking-glove sensory loss among tests of pin-pain, vibration, joint position, fine touch, or touch-pressure sensation. Subjects with a single abnormality among symptoms, sensation, or reflexes were labeled "possible" clinical neuropathy. "Confirmed" clinical neuropathy required a diagnosis of possible or probable clinical neuropathy and abnormal electrodiagnostic testing consisting of at least one abnormal nerve conduction measure in two peripheral nerves. ${ }^{5}$

The electrodiagnostic definition of abnormality was based on evaluation of the median sensory and motor, sural sensory, and peroneal motor nerves. Subjects without symptoms or signs of neuropathy who had at least one abnormal nerve conduction measure in two peripheral nerves were described as having "subclinical" neuropathy. Summary amplitude and conduction velocity Z-scores were calculated for motor and sensory nerves using nerve conduction results obtained from referent subjects. Data were inspected to determine whether they needed to be transformed before analyses to make them more symmetrical. Amplitude Z-scores were calculated using distal amplitude measures. Conduction velocity Z-scores were calculated using distal latency, terminal conduction velocity (for sensory nerves), and extremity conduction velocity information after transforming latency measures (negative values), so that a higher value always indicated faster conduction.

Isolated nerve conduction abnormalities were identified based on the definitions of abnormality listed in Table 1. In addition, we used a second criterion for identifying a median mononeuropathy, based on the median sensory distal latency minus the ulnar sensory distal latency. This relative criterion is superior to an absolute median latency abnormality, because it controls for the influences of age, disease state, and limb temperature. ${ }^{34,46}$ We used two definitions of relative abnormality, $0.5 \mathrm{~ms}$ and $0.8 \mathrm{~ms}$. The first is considered evidence of an equivocal abnormality, whereas the second is a more definitive indication of abnormality based on the 95 th percentile of values derived from normal active workers. ${ }^{37}$

Data Management and Analyses. All data were computerized using double entry and hand checking to insure accuracy. The frequencies of symptoms, clinical signs, and neurological diagnoses were tabulated. Univariate descriptive statistics were examined 


\begin{tabular}{|c|c|c|c|c|c|}
\hline & $\begin{array}{l}\text { Definition of } \\
\text { abnormality }\end{array}$ & Group & $N$ & Mean (SD) & $P$-value* \\
\hline \multicolumn{6}{|l|}{ Sensory } \\
\hline \multicolumn{6}{|l|}{ Median } \\
\hline \multirow[t]{2}{*}{ Amplitude $(\mu \mathrm{V})$} & $<10.0$ & Chlorpyrifos & 53 & $29(12.8)$ & 0.42 \\
\hline & & Referent & 60 & $31(12.3)$ & \\
\hline \multirow{2}{*}{$\begin{array}{l}\text { Terminal conduction } \\
\text { velocity }(\mathrm{CV})(\mathrm{m} / \mathrm{s})\end{array}$} & $<50.0^{\dagger}$ & Chlorpyrifos & 53 & $54.8(6.7)$ & 0.70 \\
\hline & & Referent & 60 & $55.3(7.0)$ & \\
\hline \multirow[t]{2}{*}{ Distal latency (ms) } & $>3.7$ & Chlorpyrifos & 53 & $3.3(0.4)$ & 0.66 \\
\hline & & Referent & 60 & $3.3(0.5)$ & \\
\hline \multicolumn{6}{|l|}{ Ulnar } \\
\hline \multirow[t]{2}{*}{ Amplitude $(\mu \mathrm{V})$} & $<10.0$ & Chlorpyrifos & 53 & $27(11.0)$ & 0.68 \\
\hline & & Referent & 60 & $28(11.1)$ & \\
\hline \multirow[t]{2}{*}{ Terminal CV (m/s) } & $<50.0+$ & Chlorpyrifos & 53 & $57.5(5.5)$ & 0.88 \\
\hline & & Referent & 60 & $57.6(5.0)$ & \\
\hline \multirow[t]{2}{*}{ Distal latency (ms) } & $>3.7$ & Chlorpyrifos & 53 & $3.2(0.2)$ & 0.99 \\
\hline & & Referent & 60 & $3.2(0.3)$ & \\
\hline \multicolumn{6}{|l|}{ Sural } \\
\hline \multirow[t]{2}{*}{ Amplitude $(\mu \mathrm{V})$} & $<6.0$ & Chlorpyrifos & 53 & $18(5.9)$ & 0.77 \\
\hline & & Referent & 60 & 18 (7.2) & \\
\hline \multirow[t]{2}{*}{ Terminal CV (m/s) } & $<40.0$ & Chlorpyrifos & 53 & $50.4(5.0)$ & 0.64 \\
\hline & & Referent & 60 & $50.0(5.1)$ & \\
\hline \multirow[t]{2}{*}{ Distal latency (ms) } & $>4.2$ & Chlorpyrifos & 53 & $3.5(0.3)$ & 0.38 \\
\hline & & Referent & 60 & $3.5(0.3)$ & \\
\hline \multicolumn{6}{|l|}{ Motor } \\
\hline \multicolumn{6}{|l|}{ Median } \\
\hline \multirow[t]{2}{*}{ Amplitude (mV) } & $<4.2$ & Chlorpyrifos & 53 & $9.4(3.1)$ & 0.27 \\
\hline & & Referent & 60 & $10.1(3.5)$ & \\
\hline \multirow[t]{2}{*}{ Forearm CV (m/s) } & $<49.0$ & Chlorpyrifos & 53 & $56.6(4.1)$ & 0.50 \\
\hline & & Referent & 60 & $57.1(3.3)$ & \\
\hline \multirow{2}{*}{ Distal latency (ms) } & $>4.4$ & Chlorpyrifos & 53 & $3.4(0.4)$ & 0.48 \\
\hline & & Referent & 60 & $3.4(0.6)$ & \\
\hline \multirow[t]{2}{*}{ F-wave latency (ms) } & $>31.8$ & Chlorpyrifos & 53 & $27.9(2.3)$ & 0.70 \\
\hline & & Referent & 60 & $27.7(2.7)$ & \\
\hline \multicolumn{6}{|l|}{ Peroneal } \\
\hline \multirow[t]{2}{*}{ Amplitude (mV) } & $<2.5$ & Chlorpyrifos & 53 & $7.2(3.6)$ & 0.79 \\
\hline & & Referent & 60 & $7.4(2.9)$ & \\
\hline \multirow[t]{2}{*}{ Distal latency (ms) } & $>6.1$ & Chlorpyrifos & 52 & $4.6(0.6)$ & 0.45 \\
\hline & & Referent & 60 & $4.5(0.6)$ & \\
\hline \multirow[t]{2}{*}{ F-wave latency (ms) } & $>56.0$ & Chlorpyrifos & 51 & $48.7(4.2)$ & 0.97 \\
\hline & & Referent & 60 & $48.7(4.9)$ & \\
\hline
\end{tabular}

*t-test for difference in means (adjusted for unequal variance between groups).

†Terminal sensory conduction velocity based on 95th percentile onset latency value of $3.2 \mathrm{~ms}$ and $2.8 \mathrm{~ms}$ for median and ulnar nerves, respectively. ${ }^{37}$

for each data element to determine the mean, standard deviation, range, and shape of the distribution. Analyses included comparison of clinical, laboratory, and electrophysiological results relevant to the evaluation of peripheral neuropathy for the chlorpyrifos group and the referent group $(t$-test for difference in means, Fisher exact test, or chi-square test for associations). All analyses were performed using SAS, version 8.2 (SAS Institute, Cary, NC).

\section{RESULTS}

Neurological Evaluation. There were no significant $(P<0.05)$ group differences for the number of subjects reporting symptoms or for the presence of neurological signs.

Symptoms. Nineteen subjects (11 chlorpyrifos, 8 referent) reported sensory symptoms of numbness, tingling, or sensory loss. Sensory symptoms were confined to one or both hands for 13 of these subjects. Five subjects reported bilateral sensory symptoms that were symmetrical, but only 2 (1 chlorpyrifos, 1 referent) reported symptoms in a stocking or stocking-glove distribution suggestive of neuropathy. Both subjects described intermittent symptoms; no subject reported persistent distal distribution sensory symp- 
toms suggestive of neuropathy. Nevertheless, we accepted any symmetrical stocking or stocking-glove sensory symptoms to be suggestive of possible neuropathy for assigning neuropathy outcome variables.

Signs. Thirteen subjects had symmetrical neurological signs. Three subjects (2 chlorpyrifos, 1 referent) had an exaggerated postural (physiological) tremor of the type sometimes associated with sensory neuropathy. The tremor was graded as mild for all 3 . Eleven subjects had signs more directly referable to the peripheral nervous system. Five subjects ( 2 chlorpyrifos, 3 referent) had decreased vibration sensation at the toes (all mild), and 2 subjects (1 chlorpyrifos, 1 referent) had decreased quantitative touch-pressure sensation at the great toe. No subject had subjectively reduced pin-pain, joint position, or fine-touch sensation. Six subjects (2 chlorpyrifos, 4 referent) had decreased or absent ankle reflexes. Three subjects (1 chlorpyrifos, 2 referent) had absent reflexes, including 1 chlorpyrifos subject with diffuse hyporeflexia and 1 referent subject who, many years before, had been prescribed a neurotoxic chemotherapy medication for successful treatment of a systemic malignancy. No subject had clinically detectable weakness or abnormal station or gait. Six subjects ( 2 chlorpyrifos, 4 referent) had a total of 8 focal (localized) abnormalities. Localized signs included extensor digitorum brevis atrophy (1 local trauma), a trace or absent ankle reflex (3 prior radiculopathy, or 1 diabetes), decreased foot sensation (2 prior radiculopathy), and decreased hand sensation (1 prior carpal tunnel syndrome).

Nerve Conduction Studies. The mean nerve conduction study results (without adjusting for factors known to influence results, such as age and anthropometric measures) are shown in Table 1. No significant group differences were found for any of the measures. All mean values were comparable to published laboratory normal control values based on subjects known to be healthy without underlying disorders associated with neuropathy. ${ }^{19,24,36,37,43,44}$ The sural response amplitudes, generally considered the most sensitive indicator of a sensory neuropathy, were comparable to published control mean values. ${ }^{47}$ No significant group differences were found for any of the summary nerve conduction Z-scores (Table 2).

The frequency of specific nerve conduction abnormalities is summarized in Table 3 . There were no significant differences between groups. Twenty-two subjects (9 chlorpyrifos, 13 referent) had some nerve conduction study abnormality. Four subjects (1
Table 2. Comparison of nerve conduction study outcome Z-score results for chlorpyrifos $(n=53)$ and referent $(n=60)$ subjects.

\begin{tabular}{llrc}
\hline & \multicolumn{1}{c}{ Group } & $\begin{array}{r}\text { Z-score mean } \\
(\mathrm{SD})\end{array}$ & $P^{\text {-value* }}$ \\
\hline Motor amplitude & Chlorpyrifos & $-0.14(1.6)$ & 0.37 \\
& Referent & $0.12(1.5)$ & \\
Motor conduction & Chlorpyrifos & $-0.25(3.4)$ & 0.48 \\
& Referent & $0.22(3.7)$ & \\
Sensory amplitude & Chlorpyrifos & $-0.15(2.5)$ & 0.54 \\
& Referent & $0.13(2.4)$ & \multirow{2}{*}{0.93} \\
Sensory conduction & Chlorpyrifos & $0.04(3.8)$ & 0.93 \\
& Referent & $-0.03(4.3)$ & \\
\hline
\end{tabular}

${ }^{*} t$-test for difference in means.

chlorpyrifos, 3 referent) fulfilled nerve conduction criteria for neuropathy, the criteria most relevant to the peripheral nervous system evaluation for potential toxic neuropathy. Eleven subjects (4 chlorpyrifos, 7 referent) had an absolute prolongation of the median sensory distal latency. When a relative distal latency criterion based on comparison of the median sensory and ulnar sensory distal latencies was used to identify the presence of a median mononeuropathy at the wrist, 12 subjects ( 8 chlorpyrifos, 4 referent) showed a median sensory distal latency minus ulnar sensory distal latency exceeding $0.5 \mathrm{~ms}$. Among the 12 subjects who fulfilled this 0.5 -ms relative criterion, 8 had an equivocal abnormality (median sensory latency minus ulnar sensory latency $>0.5 \mathrm{~ms}$ but $<0.8 \mathrm{~ms}$ ). Three subjects ( 1 chlorpyrifos, 2 referent) fulfilled the more definitive indication based on a median sensory distal latency minus ulnar sensory distal latency $>0.8 \mathrm{~ms}$. All 3 had symptoms of carpal tunnel syndrome. Three additional subjects ( 2 chlorpyrifos, 1 referent) had an isolated ulnar sensory abnormality, and 5 subjects (3 chlorpyrifos, 2 referent) had an isolated peroneal abnormality identified by a low motor response amplitude (3) or prolonged F-wave latency (2). Two of 3 subjects with a low peroneal motor response amplitude had focal atrophy of the extensor digitorum brevis muscle and the third subject had anomalous peroneal innervation, a variant of normal. Both subjects with an isolated F-wave abnormality were tall, and the slight prolongations were not considered abnormal after correction for height. Two subjects (both in the referent group) showed a prolonged sural distal latency; no subject had an abnormal sural amplitude.

Outcome Variables. The number of subjects fulfilling the outcome criteria for neuropathy did not differ significantly between groups. Two subjects (1 in each group) had evidence of subclinical neurop- 


\begin{tabular}{|c|c|c|c|}
\hline Finding & Group & N & $P$-value ${ }^{\star}$ \\
\hline \multicolumn{4}{|l|}{ Diffuse or multifocal abnormality } \\
\hline \multirow[t]{2}{*}{ NCS abnormality in $>1$ nerve $^{\dagger}$} & Chlorpyrifos & 1 & 0.62 \\
\hline & Referent & 3 & \\
\hline \multirow[t]{2}{*}{ Any NCS abnormality } & Chlorpyrifos & 9 & 0.53 \\
\hline & Referent & 13 & \\
\hline \multicolumn{4}{|l|}{ Specific NCS abnormalities } \\
\hline \multicolumn{4}{|l|}{ Median sensory } \\
\hline \multirow[t]{2}{*}{ Prolonged sensory latency } & Chlorpyrifos & 4 & 0.50 \\
\hline & Referent & 7 & \\
\hline \multirow[t]{2}{*}{ Median-ulnar sensory latency $>0.5 \mathrm{~ms}$} & Chlorpyrifos & 8 & 0.22 \\
\hline & Referent & 4 & \\
\hline \multirow[t]{2}{*}{ Median-ulnar sensory latency $>0.8 \mathrm{~ms}$} & Chlorpyrifos & 1 & $>0.99$ \\
\hline & Referent & 2 & \\
\hline \multirow[t]{2}{*}{ Ulnar sensory } & Chlorpyrifos & 2 & 0.60 \\
\hline & Referent & 1 & \\
\hline \multirow[t]{2}{*}{ Sural } & Chlorpyrifos & 0 & 0.50 \\
\hline & Referent & 2 & \\
\hline \multirow[t]{2}{*}{ Peroneal motor } & Chlorpyrifos & 3 & 0.55 \\
\hline & Referent & 2 & \\
\hline
\end{tabular}

*Fisher's exact two-tailed $P$ or chi-square.

${ }^{\dagger}$ Among median motor, median sensory, peroneal, or sural nerves, and therefore fulfilling nerve conduction study (NCS) criteria for polyneuropathy

athy, based on nerve conduction abnormalities in more than one nerve without symptoms or signs suggestive of neuropathy. Eleven subjects (4 chlorpyrifos, 7 referent) fulfilled criteria for possible neuropathy, indicating the presence of a single appropriate abnormality consistent with neuropathy among symptoms, sensation, or reflexes. Two subjects ( 1 in each group) had two appropriate abnormalities among sensation and reflexes, fulfilling criteria for probable neuropathy. Two subjects (both in the referent group) had confirmed neuropathy, based on fulfilling criteria for possible neuropathy in conjunction with nerve conduction abnormalities in more than one nerve. None of the subjects with probable or confirmed neuropathy reported symptoms of neuropathy and all had signs described as mild or equivocal. Both subjects with confirmed neuropathy showed decreased touch-pressure sensation in the feet that was described as equivocal, normal ankle reflexes, and borderline conduction abnormalities with normal sural response amplitude. Both of these subjects were tall (near $1.9 \mathrm{~m}$ ), heavy (over $105 \mathrm{~kg}$ ), and had an elevated body mass index (both exceeded 30). The examining neurologist attributed the mild sensory findings to body size for both subjects.

\section{DISCUSSION}

The results of this cross-sectional study are important for several reasons. We evaluated workers who had measurable occupational exposure to chlorpyrifos. Documentation of exposure is critical to the interpretation of any epidemiological study. Our exposure measures included systematic exposure histories, historical air monitoring data, and biological measures of chlorpyrifos metabolism and cholinesterase activities. The historical exposure estimates established that the chlorpyrifos subjects had longterm chlorpyrifos exposure, averaging almost a decade over time, that differed greatly in magnitude and duration from exposure experienced by referents. The biological exposure assessments allowed us to document chlorpyrifos exposure contemporaneously with our evaluations. Chlorpyrifos subjects showed significantly higher TCP excretion and lower plasma BuChE activities than referents, indicating chlorpyrifos exposure at levels where well-described physiological effects on B-esterases exist. The estimated daily urine excretion of TCP suggested an average daily chlorpyrifos exposure of approximately $17 \%$ (range $0-115 \%$ ) of that received by a typical subject exposed during a working day at the permissible chlorpyrifos exposure level of $200 \mu \mathrm{g} / \mathrm{m}^{3}$. Nevertheless, the range of exposures among chlorpyrifos subjects based on TCP excretion over the entire study year varied from no exposure to exposure at approximately $250 \%$ of the permissible exposure level. ${ }^{4}$ The chlorpyrifos exposure levels for some subjects were substantial, but TCP excretion was unrelated to inhibition of $\mathrm{AChE}$, suggesting that the 
internal dose was below the range where this physiological effect exists.

Although a few referent subjects had occasionally worked in chlorpyrifos-exposed jobs in past years, their cumulative exposure estimates were dramatically lower than among the chlorpyrifos workers. In a stratified probability sample of the U.S. general population, the average aggregate long-term exposure of adults to chlorpyrifos was $0.19 \mu \mathrm{g} / \mathrm{kg}$. day. ${ }^{12,21}$ The urine TCP level among our referent subjects of $4.3 \mu \mathrm{g} / \mathrm{g} \mathrm{Cr}$ back-calculates to a daily chlorpyrifos dose of $0.22 \mu \mathrm{g} / \mathrm{kg} \cdot$ day (based on $70 \%$ excretion and 88-kg mean weight of our subjects), a level quite similar to the amounts observed in the U.S. adult general population.

The chlorpyrifos subjects we studied were representative of workers involved in the various aspects of manufacturing chlorpyrifos. This is essential because persons engaged in the manufacture of chlorpyrifos had been identified prior to evaluation as an important study cohort. ${ }^{3}$ We had excellent and comparable participation of exposed and referent subjects, and the occupational referent group was similar to the exposed group in factors important to our evaluation of the nervous system. ${ }^{43}$ All examiners were masked to the exposure status of individual subjects. This was a healthy population of workers, with little evidence of systemic illnesses such as diabetes mellitus (1 subject in each group) that could camouflage detection of chlorpyrifos-related neurological dysfunction. The outcome variables used standard clinical criteria for neuropathy, assuring the sensitivity and specificity of the methodology for detecting clinically evident neuropathy. ${ }^{14,15}$ The quantitative measures of sensory and motor nerve function had sufficient power to detect small group differences suggestive of subclinical neuropathy, with $80 \%$ power to detect differences between the groups of $6.5 \mu \mathrm{V}$ or greater for median sensory amplitude, 0.24 ms for median sensory distal latency, $3.4 \mu \mathrm{V}$ for sural amplitude, and $0.15 \mathrm{~ms}$ for sural distal latency.

We found little evidence of peripheral nervous system problems among these subjects. Only 2 subjects (1 in each group) reported symptoms consistent with a sensory or sensorimotor neuropathy. The few subjects with clinical or electrodiagnostic findings suggestive of neuropathy were equally divided between the exposed and unexposed groups, and all had explanations other than chlorpyrifos exposure for their findings. We also found no evidence of subclinical neuropathy. Our clinical results corroborate the surveillance data reported for Dow Chemical Company employees, which showed that the prevalence of neuropathy was not significantly in- creased among employees potentially exposed to chlorpyrifos compared to unexposed referents. ${ }^{9}$

It is difficult to reconcile the disparate peripheral nervous system results across other studies. Many of the studies are subject to methodological problems acknowledged by the authors. These problems include limited exposure measures, reliance on nonspecific symptoms of neuropathy, and unconventional definitions of neuropathy that frequently reflect the results of quantitative sensory testing, without information about clinical signs or electrodiagnostic results. At present, the reports attributing sensory neuropathy to long-term, low-level exposures to chlorpyrifos and other OP insecticides describe dissimilar symptoms, signs, and test results that do not represent a specific syndrome attributable to OP exposure.

Several studies attributing a large-fiber neuropathy to OP insecticide exposure have done so on the basis of differences in quantitative sensory thresholds among OP-exposed subjects compared to referents. ${ }^{26,42,45}$ A single study attributing a small-fiber sensory neuropathy to OP insecticide exposure was based on thermal thresholds. ${ }^{22}$ We did not utilize quantitative sensory testing as part of our evaluation, in part, because the results are thought to parallel those of the sensory nerve conduction studies. ${ }^{33}$ Furthermore, quantitative sensory testing is subject to influences unrelated to neuropathy, and it is generally accepted that the results of quantitative sensory testing should not be the sole criterion to diagnose pathology. ${ }^{40}$ In contrast, nerve conduction measures such as sensory response amplitude are objective and specific indicators of sensory neuropathy. Sural nerve testing is important, as an abnormal sural response is generally accepted as one of the most sensitive indicators of a sensory neuropathy. No subject we examined had an undetectable sural response, or even an amplitude below the lower limit of normal. We therefore found no subject among the 53 chlorpyrifos manufacturers who resembled the 8 chlorpyrifos-exposed individuals with sensory neuropathy characterized by abnormal sural nerve conduction study results reported by Kaplan and associates. ${ }^{23}$ None of the 8 individuals they reported described symptoms of an acute cholinergic syndrome suggestive of chlorpyrifos overexposure, and no cholinesterase levels were measured contemporaneously with exposure. We also found no subject who resembled the 6 chlorpyrifos-exposed termite control applicators who had severely depressed BuChE activities and reduced sural conduction velocities reported by Gotoh et al. ${ }^{18}$ In that study, neither symptoms nor signs of neuropathy were re- 
ported, and all 6 subjects had median and ulnar conduction velocities near the upper limit of normal. The electrodiagnostic techniques and limb temperature also were not described, and the sensory response amplitudes (the most important information in axonal-loss neuropathy) were not reported. However, it is evident that sural responses must have been present bilaterally among all 6 subjects because the authors calculated conduction velocities. Although the sural conduction velocities showed substantial slowing, the normal ranges provided suggest that the authors may have used the response peak, not the onset, in their calculations, and the velocities therefore may not reflect conduction of the fastest conducting fibers. These and other problems make it difficult to interpret the findings from their study.

Finally, we found no association between any other peripheral problem, such as a median mononeuropathy, and chlorpyrifos exposure. We included an investigation for median mononeuropathy, based on the hypothesis that subclinical neuropathy may increase susceptibility to cumulative nerve trauma or entrapment neuropathy. ${ }^{1}$ Twelve of the 113 subjects we examined $(11 \%)$ fulfilled conventional criterion for median mononeuropathy of the dominant hand. This frequency is substantially less than the frequencies reported using the same criterion among active workers of $25 \%$ for either hand ${ }^{46}$ or $16 \%$ for the dominant hand. ${ }^{38}$ The lower frequency of median mononeuropathy among the chemical workers we studied likely reflects the small number of jobs involving high levels of hand repetition or the use of forceful grip.

In this cross-sectional investigation, we found no evidence that long-term occupational exposure to chlorpyrifos was associated with sensory neuropathy or findings suggestive of subclinical neuropathy. Our results do not preclude the possibility that exposure to other OP insecticides or mixtures of OP compounds under different circumstances may have effects we did not observe. However, the results provide no support for the hypothesis that sensory neuropathy or other isolated peripheral abnormalities are related to chlorpyrifos exposure at levels associated with the manufacturing process, which, for some subjects, included exposures at or above the permissible exposure level and sufficient to produce biological effects on BuChE activity.

This study was financially supported by Dow AgroSciences, Indianapolis, Indiana, with additional support from Dow Chemical Company and the Dow Chemical Company Foundation. We acknowledge the additional investigators on this project, including Brenda Gillespie, PhD, Bruno Giordani, PhD, Steven P. Levine, $\mathrm{PhD}$, and Jonathon Raz, PhD (deceased), and other members of the Chlorpyrifos Study team, including Jennifer N. Baughman, Zhuolin $\mathrm{Li}$, and James A. Wolfe. We also acknowledge the receipt of a SPHERE (Supporting Public Health and Environmental Research Efforts) Award from the Dow Chemical Company Foundation, for which the authors express their gratitude, and the assistance provided to us by the many Dow Chemical Company and Dow AgroSciences employees who assisted at various points in supporting this research. Finally, we are indebted to the Dow Chemical Company employees who volunteered their time as subjects in this study.

Disclosure: Some of the authors have at times been retained as consultants or served as expert witnesses in litigation for firms or companies, including Dow Chemical Company and Dow AgroSciences, concerned with the manufacture or use of insecticides. Support of these activities has included both personal and institutional remuneration.

\section{REFERENCES}

1. Albers JW, Brown MB, Sima AAF, Greene DA. Frequency of median mononeuropathy in patients with mild diabetic neuropathy in the early diabetes intervention trial (EDIT). Muscle Nerve 1996;19:140-146.

2. Albers JW, Cavender GF, Levine SP, Langolf GD. Asymptomatic sensorimotor polyneuropathy in workers exposed to elemental mercury. Neurology 1982;32:1168-1174.

3. Albers JW, Cole P, Greenberg RS, Mandel JS, Monson RR, Ross JH, Snodgrass WR, Spurgeon A, van Gemert M. Analysis of chlorpyrifos exposure and human health: expert panel report. J Toxicol Environ Health Part B Crit Rev 1999;2:301-324.

4. Albers JW, Garabrant DH, Schweitzer SJ, Garrison RP, Richardson RJ, Berent $\mathrm{S}$. The effects of occupational exposure to chlorpyrifos on the peripheral nervous system: a prospective cohort study. Environ Occup Med (in press)

5. Albers JW, Wald JJ, Werner RA, Franzblau A, Berent S. Absence of polyneuropathy among workers previously diagnosed with solvent-induced toxic encephalopathy. J Occup Environ Med 1999;41:500-509.

6. Ames RG, Steenland K, Jenkins B, Chrislip D, Russo $\mathrm{J}$. Chronic neurologic sequelae to cholinesterase inhibition among agricultural pesticide applicators. Arch Environ Health 1995;50:440-444.

7. Beach JR, Spurgeon A, Stephens R, Heafield T, Calvert IA, Levy LS, Harrington JM. Abnormalities on neurological examination among sheep farmers exposed to organophosphorous pesticides. Occup Environ Med 1996;53:520-525.

8. Blain PG. Adverse health effects after low dose exposure to organophosphates. Occup Environ Med 2001;58:689-690.

9. Burns CJ, Cartmill JB, Powers BS, Lee MK. An update of the morbidity experience among employees potentially exposed to chlorpyrifos. Occup Environ Med 1998;55:65-70.

10. Capodicasa E, Scapellato ML, Moretto A, Caroldi S, Lotti M. Chlorpyrifos-induced delayed polyneuropathy. Arch Toxicol 1991;65:150-155.

11. Clegg DJ, van Gemert M. Expert panel report of human studies on chlorpyrifos and/or other organophosphate exposures. J Toxicol Environ Health B Crit Rev 1999;2:257-279.

12. Cochran RC. Appraisal of risks from nonoccupational exposure to chlorpyrifos. Regul Toxicol Pharmacol 2002;35:105121.

13. Diabetes Control and Complications Trial (DCCT) Research Group. Effect of intensive diabetes treatment on nerve conduction in the Diabetes Control and Complications Trial. Ann Neurol 1995;38:869-880.

14. Diabetes Control and Complications Trial Research Group. The effect of intensive diabetic therapy on the development 
and progression of neuropathy. Ann Intern Med 1995;122: 561-568.

15. Dyck PJ. Peripheral neuropathy. Changing concepts, differential diagnosis and classification. Med Clin N Am 1968;52: 895-908.

16. Dyck PJ. Detection, characterization, and staging of polyneuropathy: assessed in diabetes. Muscle Nerve 1988;11:21-32.

17. Dyck PJ, Litchy WJ, Lehman KA, Hokanson JL, Low PA, O'Brien PC. Variables influencing neuropathic endpoints: the Rochester Diabetic Neuropathy Study of Healthy Subjects. Neurology 1995;45:1115-1121.

18. Gotoh M, Saito S, Huang J, Fukaya Y, Matsumoto T, Hisanaga N, Shibata E, Ichihara G, Kamijima M, Takeuchi Y. Changes in cholinesterase activity, nerve conduction velocity, and clinical signs and symptoms in termite control operators exposed to chlorpyrifos. J Occup Health 2001;43:157-164.

19. Greene DA, Sima AF, Pfeifer MA, Albers JW. Diabetic neuropathy. Annu Rev Med 1990;41:303-317.

20. Gutmann L, Besser R. Organophosphate intoxication: pharmacologic, neurophysiologic, clinical, and therapeutic considerations. Semin Neurol 1990;10:46-51.

21. Hill RH Jr, Head SL, Baker S, Gregg M, Shealy DB, Bailey SL, Williams CC, Sampson EJ, Needham LL. Pesticide residues in urine of adults living in the United States: reference range concentrations. Environ Res 1995;71:99-108.

22. Jamal GA, Hansen S, Pilkington A, Buchanan D, Gillham RA Abdel-Azis M, Julu PO, Al Rawas SF, Hurley F, Ballantyne JP. A clinical neurological, neurophysiological, and neuropsychological study of sheep farmers and dippers exposed to organophosphate pesticides. Occup Environ Med 2002;59: 434-441.

23. Kaplan JG, Rosenberg NL, Pack D, Schaumburg HH. Sensory neuropathy associated with Dursban (chlorpyrifos) exposure. Neurology 1993;43:2193-2196.

24. Letz R, Gerr F. Covariates of human peripheral nerve function: I-nerve conduction velocity and amplitude. Neurotoxicol Teratol 1994;16:95-104.

25. Linz DH, Suskind RR, Lockey JE, Keebler PJ, Shukla R, Rice $\mathrm{CH}$, Pflaumer JE, McKay RT, Livingston GK, Albert RE. Health status of pesticide applicators with attention to the peripheral nervous system. J Argomed 1994;1:23-42.

26. London L, Nell V, Thompson ML, Myers JE. Effects of long term organophosphate exposures on neurological symptoms, vibration sense and tremor among South African farm workers. Scand J Work Environ Health 1998;24:18-29

27. Lotti M. The pathogenesis of organophosphate polyneuropathy. Crit Rev Toxicol 1991;21:465-487.

28. Lotti M. Low-level exposures to organophosphorus esters and peripheral nerve function. Muscle Nerve 2002;25:492-504.

29. Lotti M, Becker CE, Aminoff MJ. Organophosphate polyneuropathy: pathogenesis and prevention. Neurology 1984;34: $658-662$.

30. Lotti M, Moretto A, Zoppellari R, Dainese R, Rizzuto N, Barusco G. Inhibition of lymphocytic neuropathy target esterase predicts the development of organophosphate-induced delayed polyneuropathy. Arch Toxicol 1986;59:176-179.

31. Moretto A, Lotti M. Poisoning by organophosphorus insecticides and sensory neuropathy. J Neurol Neurosurg Psychiatry 1998;64:463-468.
32. Pilkington A, Buchanan D, Jamal GA, Gillham R, Hansen S, Kidd M, Hurley JF, Soutar CA. An epidemiological study of the relations between exposure to organophosphate pesticides and indices of chronic peripheral neuropathy and neuropsychological abnormalities in sheep farmers and dippers. Occup Environ Med 2001;58:702-710.

33. Redmond JM, McKenna MJ, Feingold M, Ahmad BK. Sensory testing versus nerve conduction velocity in diabetic polyneuropathy. Muscle Nerve 1992;15:1334-1339.

34. Redmond MD, Rivner MH. False positive electrodiagnostic tests in carpal tunnel syndrome. Muscle Nerve 1988;11:511-517.

35. Richardson RJ. Assessment of the neurotoxic potential of chlorpyrifos relative to other organophosphorus compounds: a critical review of the literature. J Toxicol Environ Health 1995;44:135-165.

36. Robinson LR, Micklesen BS, Wang L. Strategies for analyzing nerve conduction data: superiority of a summary index over single tests. Muscle Nerve 1998;21:1166-1171.

37. Salerno DF, Franzblau A, Werner RA, Bromberg MB, Armstrong TJ, Albers JW. Median and ulnar nerve conduction studies among workers: normative values. Muscle Nerve 1998; 21:999-1005.

38. Salerno DF, Werner RA, Albers JW, Becker MP, Armstrong TJ, Franzblau A. Reliability of nerve conduction studies among active workers. Muscle Nerve 1999;22:1372-1379.

39. Senanayake N, Johnson MK. Acute polyneuropathy after poisoning by a new organophosphate insecticide. N Engl J Med 1982;306:155-157.

40. Shy ME, Frohman EM, So YT, Arezzo JC, Cornblath DR, Giuliani MJ, Kincaid JC, Ochoa JL, Parry GJ, Weimer LH. Quantitative sensory testing: report of the Therapeutics and Technology Assessment Subcommittee of the American Academy of Neurology. Neurology 2003;60:898-904.

41. Steenland K, Jenkins B, Ames RG, O'Malley M, Chrislip D, Russo J. Chronic neurological sequelae to organophosphate pesticide poisoning. Am J Publ Health 1994;84:731-736.

42. Steenland K, Jenkins B, Ames RG, O’Malley M, Chrislip D, Russo J. Chronic neurological sequelae to organophosphate pesticide poisoning. Am J Publ Health 1994;84:731-736.

43. Stetson DS, Albers JW, Silverstein BA, Wolfe RA. Effects of age, sex, and anthropometric factors on nerve conduction measures. Muscle Nerve 1992;15:1095-1104.

44. Stetson DS, Silverstein BA, Keyserling WM, Wolfe RA, Albers JW. Median sensory distal amplitude and latency: comparisons between nonexposed managerial/professional employees and industrial workers. Am J Indust Med 1993;24:175189

45. Stokes L, Stark A, Marshall E, Narang A. Neurotoxicity among pesticide applicators exposed to organophosphates. Occup Environ Med 1995;52:648-653.

46. Werner RA, Franzblau A, Albers JW, Armstrong TJ. Median mononeuropathy among active workers: are there differences between symptomatic and asymptomatic workers? Am J Indust Med 1998;33:374-378.

47. Wilbourn AJ. Sensory nerve conduction studies. J Clin Neurophysiol 1994;11:584-601.

48. Woods HF, and the Working Group on Organophosphates. Committee on Toxicity of Chemicals in Food, Consumer Products and the Environment. Department of Health, United Kingdom; 1999. p 1-7. 